\title{
Squamoid eccrine ductal carcinoma: a case report
}

\author{
Zeynep Bayramoğlu ${ }^{\oplus}$, Betül Ünal \\ ${ }^{1}$ Department of Pathology, University of Health Sciences, Konya Training and Research Hospital, Konya, Turkey \\ ${ }^{2}$ Department of Medical Pathology, Akdeniz University School of Medicine, Antalya, Turkey
}

\begin{abstract}
Squamoid eccrine ductal carcinoma (SEDC) is a subtype of malignant tumours of skin appendices, showing eccrine and apocrine differentiation. It is a rare tumour and making a histopathological diagnosis is difficult. Our patient was a 79-year-old male, presenting to our hospital with the complaint of a long-term persistent wound in the scalp. An excisional biopsy was performed due to a preliminary diagnosis of a pyogenic granuloma. However, the patient was diagnosed with squamoid eccrine ductal carcinoma. Although an excisional biopsy was performed, the tumour was present on the surgical margins. Consequently, the patient underwent an extended re-excision but the tumour was detected at the surgical margins again. We aimed to present this case as SEDC is a rare tumour.

Keywords: Eccrine gland, appendageal skin tumour, squamous eccrine ductal carcinoma, squamous cell carcinoma
\end{abstract}

$\mathrm{S}$ quamoid eccrine ductal carcinoma (SEDC) is an extremely rare cutaneous tumor [1]. SEDC is clinically important because it is a potential for locoregional aggressiveness and metastasis. In histopathological examination, the tumour is biphasic with two different components, superficial and deeper areas showing different patterns. Therefore, superficial biopsies may lead to a misdiagnosis of squamous cell carcinoma (SCC) as the biopsy specimen will most likely be composed of tissues showing a squamous differentiation [2]. Herein we report a case of 79-yearold male patient with SEDC in the scalp.

\section{CASE PRESENTATION}

A 79-year-old male patient presented to our hospital with the complaint of a long-term persistent wound in the scalp. His medical history revealed that the patient had diabetes mellitus, chronic obstructive pulmonary disease, and benign prostatic hyperplasia. A protuberant, red, and ulcerated lesion of $1.2 \mathrm{~cm}$ in diameter was present on the scalp. An excisional biopsy was performed due to a preliminary diagnosis of pyogenic granuloma. In the macroscopic examination, a protuberant lesion of $1.2 \times 1 \times 0.4 \mathrm{~cm}$ in size, red in colour, and having an ulcerated surface was observed with its base adjacent to the surgical margins. The microscopic examination revealed lobules and tumour cell islets with squamous differentiation in the superficial areas (Figs. 1 and 2). In the deeper areas, an infiltrative growth pattern and irregular cords were present. In the desmoplastic stroma, tumour cells were observed showing ductal differentiation (Fig. 3). Mitoses were observed especially in areas with squamous differentiation (Fig. 


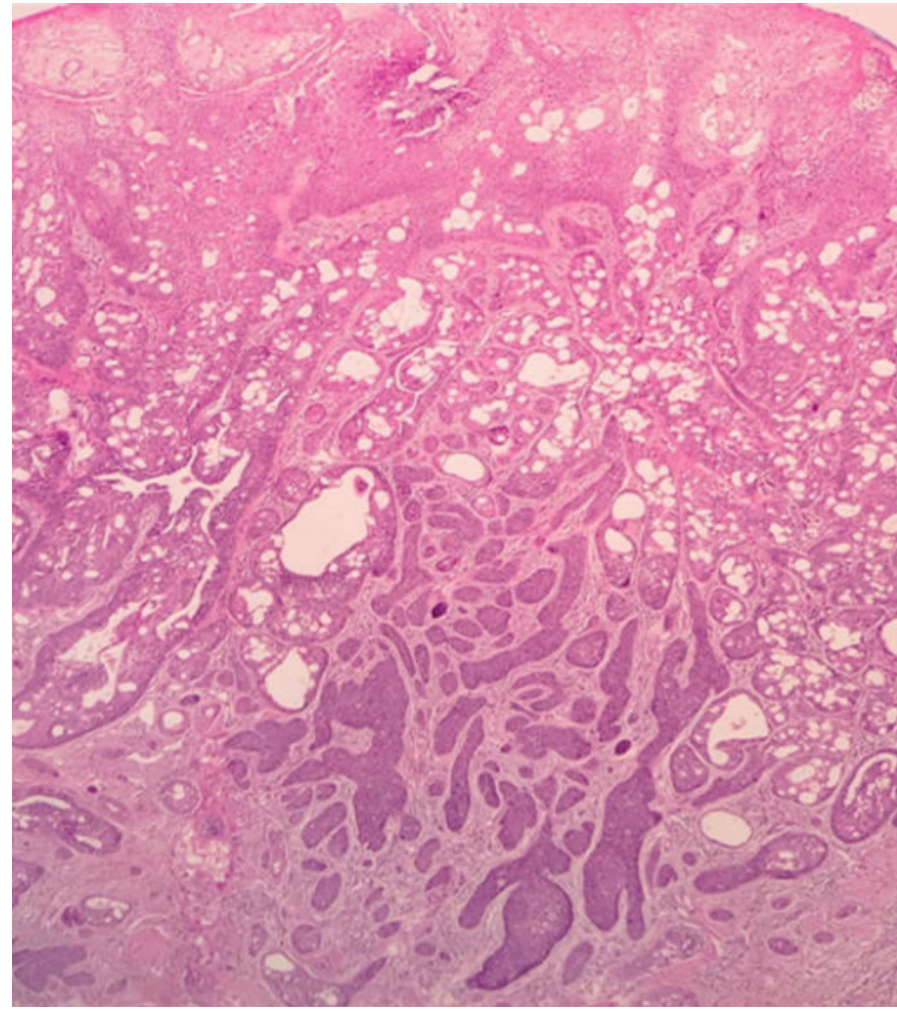

Fig.1. The light microscopic appearance of the lesion (Hematoxylin-eosin stain, $\times 40$ ).

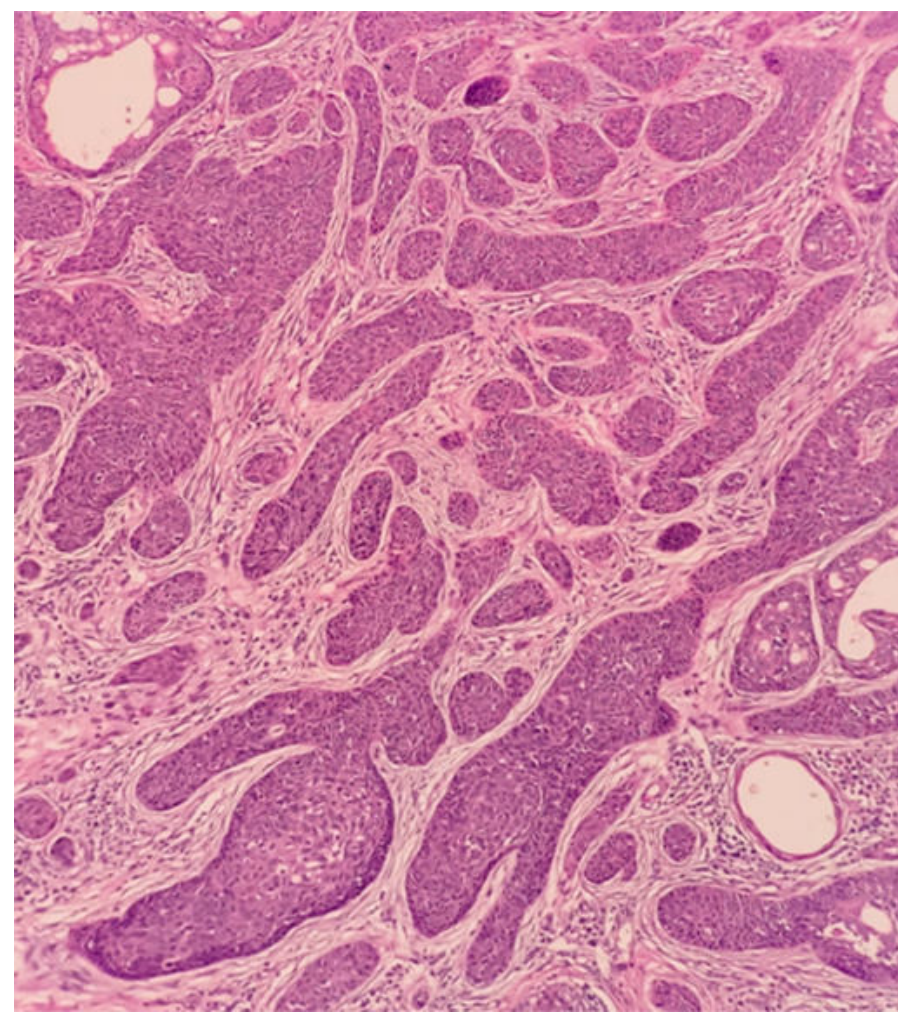

Fig.3. Infiltrative growth pattern and ductal differentiation areas in desmoplastic stroma in deep areas of the tumor (Hematoxylin-eosin stain, $\times \mathbf{1 0 0})$.

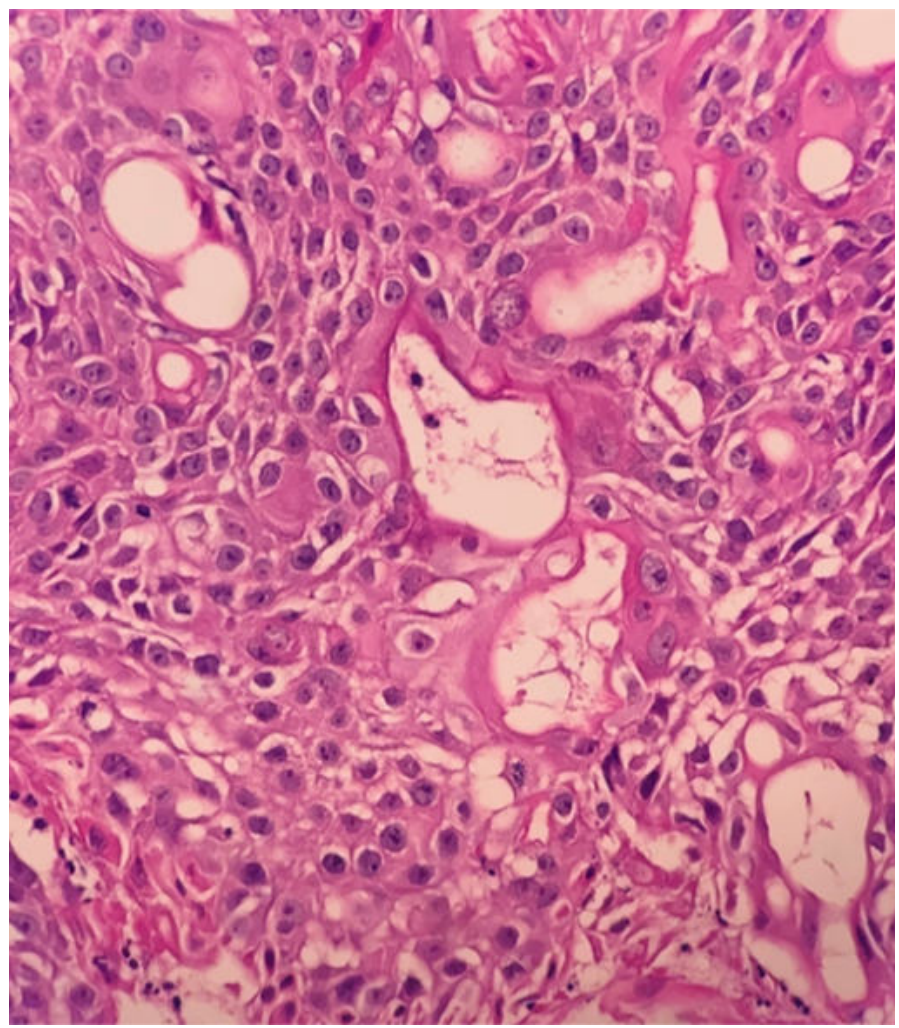

Fig.2. Squamous differentiation areas in the superficial part of the tumor (Hematoxylin-eosin stain, $\times \mathbf{2 0 0}$ ).

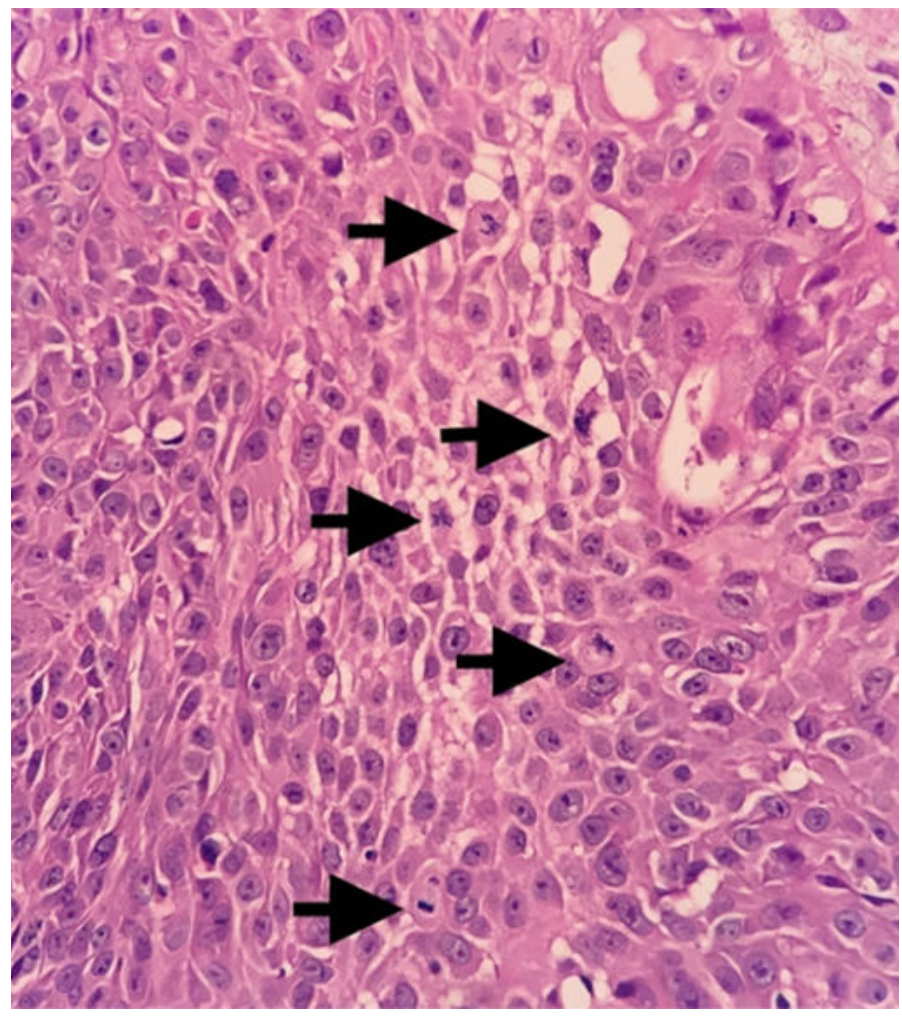

Fig.4. Mitosis in areas of squamous differentiation (Hematoxylin-eosin stain, $\times 400)$. 


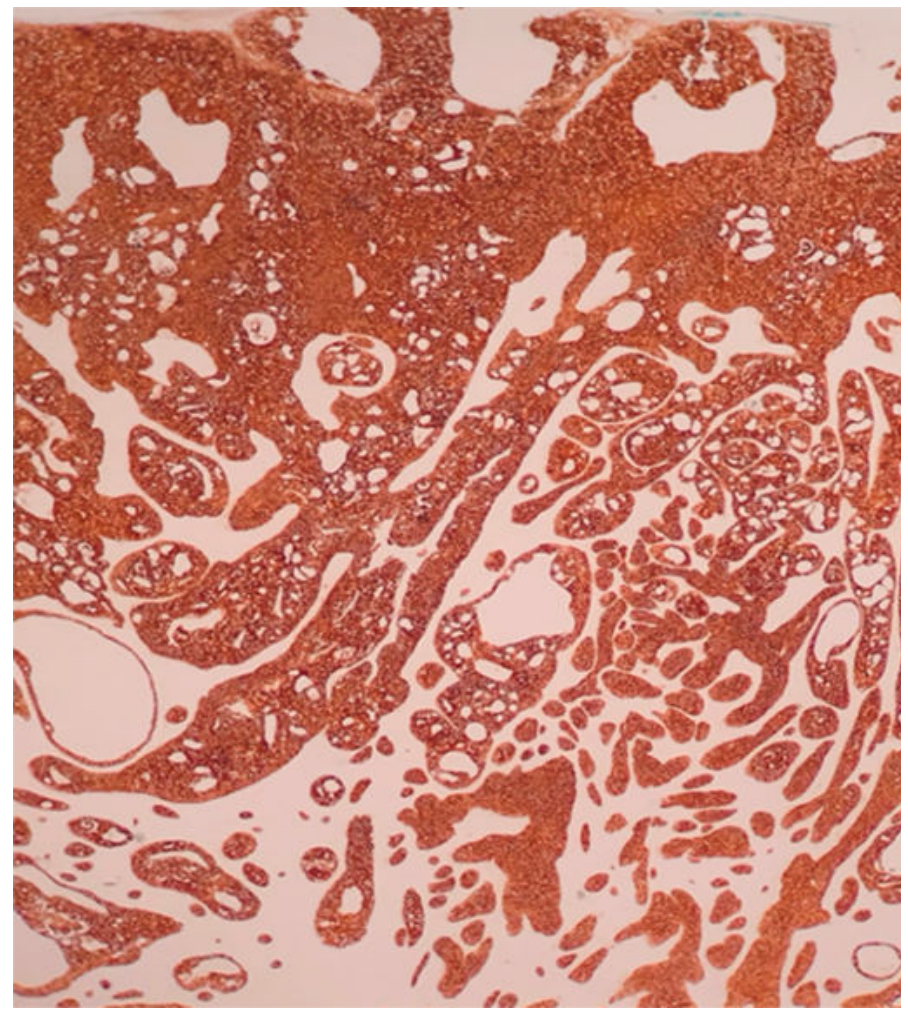

Fig.5. Positive reaction with immunohistochemistry CK5 / 6 $(\times 40)$.

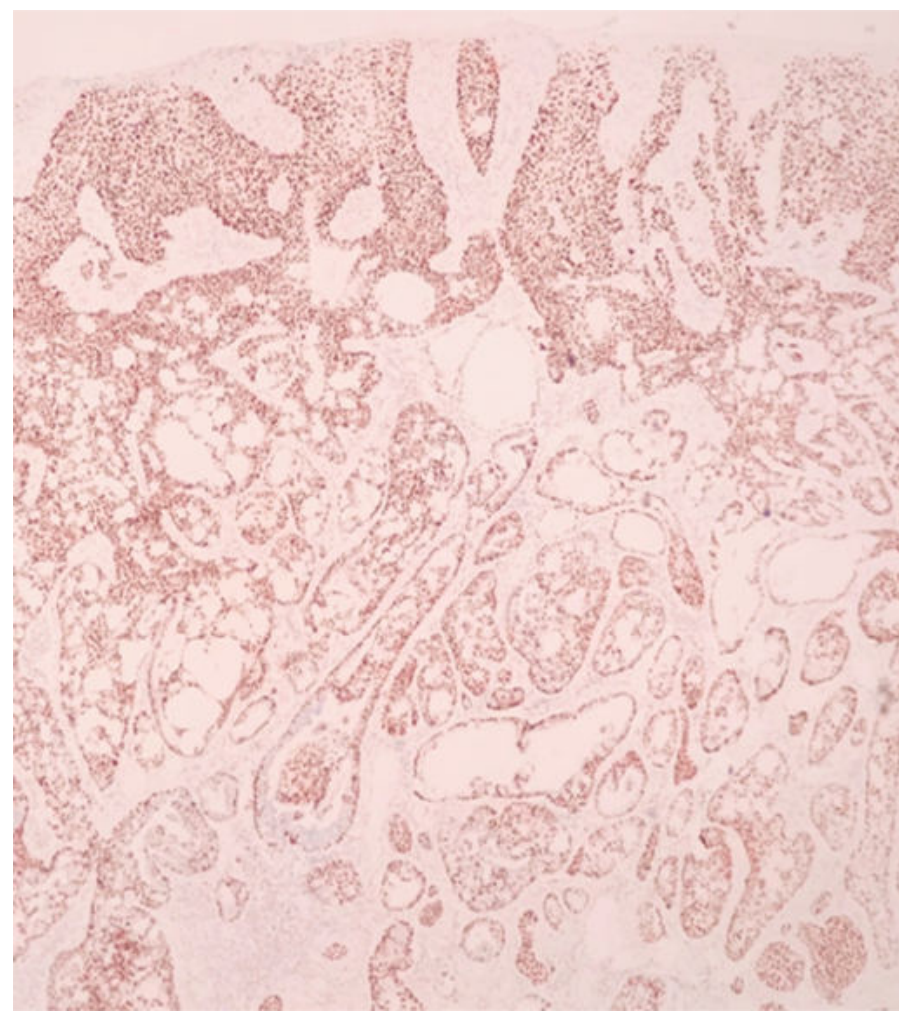

Fig.7. Positive reaction with immunohistochemistry p63 (×40).

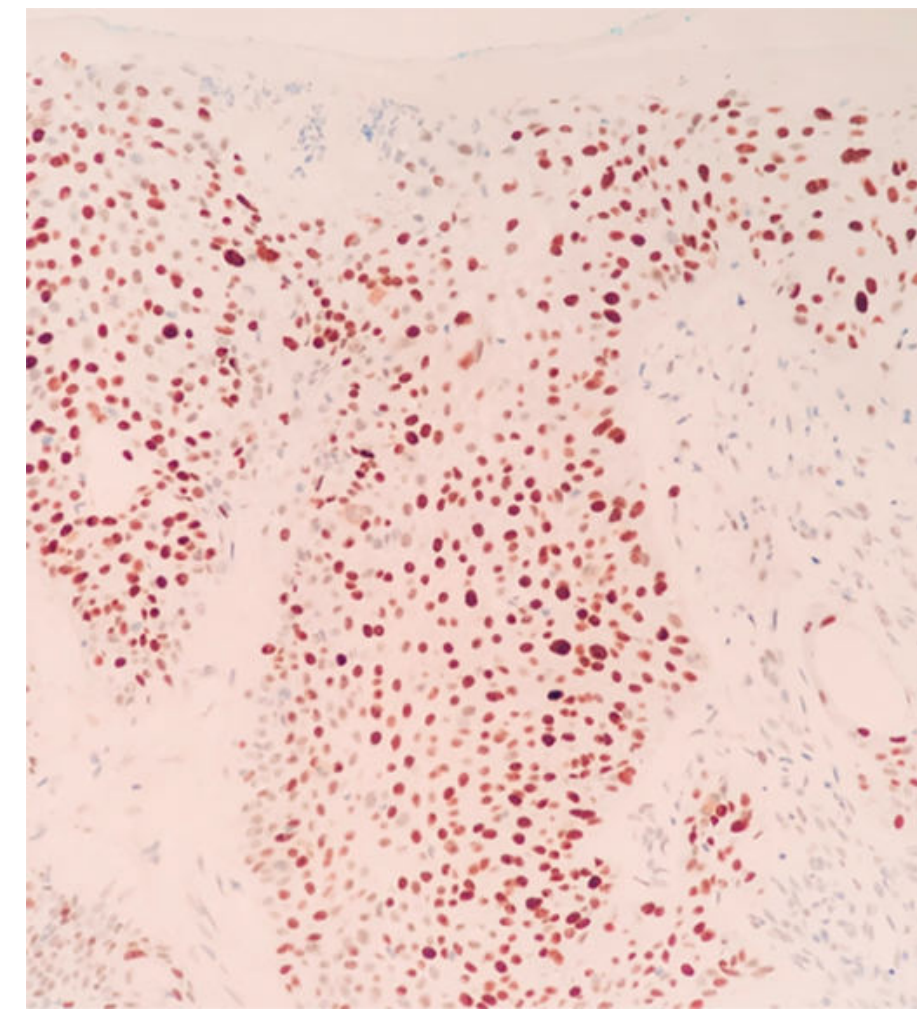

Fig.6. Positive reaction with immunohistochemistry p53 (×200).

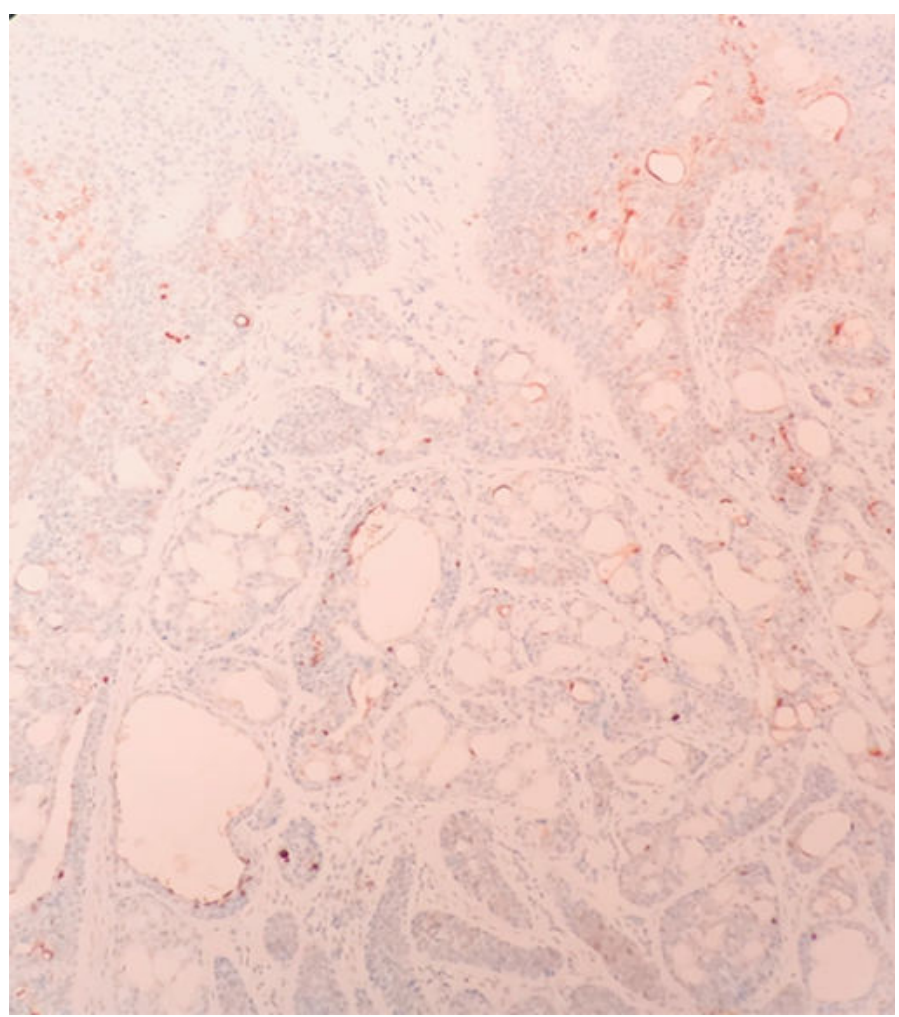

Fig.8. Positive reaction with immunohistochemistry EMA in ductal differentiation areas $(\times 100)$. 
4). No lymphovascular or perineural invasion was observed. In the immunohistochemical examination; a positive reaction was observed with $\mathrm{P} 63, \mathrm{CK} 5 / 6$, and P53 in the area of squamous differentiation, and another positive reaction was observed with CEA and EMA at the area of ductal differentiation (Figs. 5 to 8). Based on the histopathological and immunohistochemical findings, a diagnosis of SEDC was made. A re-excision was performed because the tumour was present in the surgical margins. The second excision confirmed the diagnosis of SEDC, however, the tumour was detected in the surgical margins again.

\section{DISCUSSION}

SEDC is a rare subtype of malignant adnexal tumours showing eccrine and apocrine differentiation [1]. SEDC was first described by Wick and Swanos in 1991 as a sub-type of eccrine carcinoma showing squamous differentiation, which may be misdiagnosed as SCC, especially in superficial biopsies [3]. In 1997, Wong et al. used the term SEDC when they reported three patients [4]. Currently, there are 60 case reports with SEDC available in the literature.

SEDC is usually seen in the head and neck region, in males older than 80 years old, who had a medical history of sun damage to the skin. The lesions are usually in the shape of nodules or plaques, and ulcerated. The case reports in the literature define a tumour diameter in the range of $0.15-1.8 \mathrm{~cm}$ with a mean of $0.43 \mathrm{~cm} \mathrm{[1].} \mathrm{The} \mathrm{tumour} \mathrm{demonstrates} \mathrm{an}$ infiltrative and malignant growth pattern in the histopathological examination, extending beyond the surgical margins. There may be atypical pleomorphic cells and atypical mitoses. The tumour is biphasic with two different components, superficial and deeper areas showing different patterns. While the superficial areas mostly show a squamous differentiation, syringomalike basaloid, angulated, and tubular structures characterised with a more infiltrative pattern are mostly observed in the deeper parts [1-8]. Therefore, superficial biopsies may lead to a misdiagnosis of SCC as the biopsy specimen will most likely be composed of tissues showing a squamous differentiation $[2,9,10]$. The differential diagnosis includes SCC, metastatic carcinoma, microcystic carcinoma with squamous differentiation, porocarcinoma with squamous differentiation, Merkel cell carcinoma, and benign neoplasms $[1,11]$.

In the differential diagnosis of eccrine neoplasms, immunohistochemical tests usually involve S-100, EMA, CK, CEA, and p63. Glandular tissues typically stain positive for EMA and CEA, supporting the adnexal origin [1]. On the other hand, epithelial malignancies, including SCC, stain negative for EMA and CEA. SEDC staining negative for EMA and CEA in the squamoid differentiation areas but positive in the areas showing ductal differentiation is a critical supporting finding for making the diagnosis [1]. CK5/6 is a high molecular weight cytokeratin, expressed normally in the stratified squamous epithelium, in the myoepithelial cells of the secretory glands, and in the epithelial cells of the apocrine excretory glands. Positive staining for CK5/6 and p63 rules out a diagnosis of metastatic carcinoma $[1,2]$. Although SEDC is recognized as a low-grade neoplasm, it is locally aggressive and bears a malignancy potential; therefore, it is an important clinical condition $[1,4,12,13]$. Because SEDC is a rare tumour, less is known of its biological behaviour and optimum treatment. Currently, the largest series available in the literature has been reported in 2016. This case series with 30 patients reported a $25 \%$ rate of local metastasis and a $13 \%$ rate of metastasis, including three lymph node metastasis and a distance metastasis [14].

\section{CONCLUSION}

In summary, we presented a patient with SEDC in this present case report. It should be recognized that there is a potential of making a misdiagnosis in these patients, especially with incisional or shave biopsies as these methods will collect tissue samples only containing areas with squamous differentiation but will exclude the parts of the lesion with ductal differentiation. These patients should be closely followed-up due to the high risk for recurrences.

\section{Informed consent}

Written informed consent was obtained from the patient for publication of this case report and any accompanying images. 


\section{Conflict of interest}

The authors declared that there are no potential conflicts of interest with respect to the research, authorship, and/or publication of this article.

\section{REFERENCES}

1. Elder DE, Massi D, Scolyer RA, Willemze R. WHO Classification of Skin Tumors. 2018;176-7.

2. Terushkin E, Leffell DJ, Futoryan T, Cowper S, Lazova R. Squamoid eccrine ductal carcinoma: a case report and review of the literature. Am J Dermatopathol 2010;32:287-92.

3. Wick MR, Swanson PE. Cutaneous Adnexal Tumors. A Guide toPathological Diagnosis. Chicago, IL: American Society of Clinical Pathologists; 1991:10-3.

4. Wong TY, Suster S, Mihm MC. Squamoid eccrine ductal carcinoma. Histopathology 1997;30:288-93.

5. Kohda M, Manabe T, Ueki H. Squamous islands in ecrine neoplasms. Am J Dermatopathol 1990;12:344-9.

6. Urso C, Paglierani M, Bondi R. Histologic spectrum of carcinomas with eccrine ductal differentiation (sweat-gland ductal carcinomas). Am J Dermatopathol 1993;15:435-40.

7. Herrero J, Monteagudo C, Jorda E, Llombart-Bosch A. Squamoid eccrine ductal carcinoma. Histopathology 1998;32:478-80.

8. Jacob J, Kugelman, L. Squamoid eccrine ductal carcinoma. Cutis 2018;101:378-80.

9. Jung YH, Jo HJ, Kang MS. Squamoid eccrine ductal carcinoma of the scalp. Korean J Pathol 2012:46;278-81.

10. Chan H, Howard V, Moir D, Dyall-Smith D. Squamoid eccrine ductal carcinoma of the scalp. Australas J Dermatol 2016;57:e117-9.

11. Ibrahim YL, Lambert S, Kazakov DV, Kaya G. An unusual morphological presentation of cutaneous squamous cell carcinoma mimicking microcystic adnexal carcinoma: a diagnostic pitfall. Dermatopathology 2018;5:64-8.

12. Chhibber V, Lyle S, Mahalingam M. Ductal eccrine carcinoma with squamous differentiation: apropos a case. J Cutan Pathol 2007;34:503-7.

13. Segars K, Gopman JM, Elston JB, Carter W, Harrington MA. Squamoid eccrine ductal carcinoma. Eplasty 2015;15:ic33.

14. van der Horst MP, Garcia-Herrera A, Markiewicz D, Martin B, Calonje E, Brenn T. Squamoid eccrine ductal carcinoma: a clinicopathologic study of 30 cases. Am J Surg Pathol 2016;40:755-60. 